\title{
PROJECTION OF INCIDENT SURFACE SOLAR RADIATION IN CHINA UNDER A CLIMATE CHANGE SCENARIO
}

\author{
YuKun Xiao ${ }^{1}$, ZhenMing $\mathrm{Ji}^{1 *}$, CongSheng $\mathrm{Fu}^{2}$, WenTao $\mathrm{Du}^{3}$, JunHua Yang ${ }^{3}$, WenJie Dong ${ }^{1}$ \\ ${ }^{1}$ School of Atmospheric Sciences, and Guangdong Province Key Laboratory for Climate Change and Natural Disaster Studies, Sun \\ Yat-sen University, Zhuhai, 519000,China - xiaoyk5@mail2.sysu.edu.cn, jizhm3@mail.sysu.edu.cn, dongwj3@mail.sysu.edu.cn \\ ${ }^{2}$ Key Laboratory of Watershed Geographic Sciences, Nanjing Institute of Geography and Limnology, Chinese Academy of Sciences, \\ Nanjing, 210008, China - csfu@ niglas.ac.cn \\ ${ }^{3}$ State Key Laboratory of Cryospheric Science, Cold and Arid Regions Environment and Engineering Research Institute, Chinese \\ Academy of Sciences, Lanzhou, 730000,China - yangjunhua@1zb.ac.cn, duwentao@1zb.ac.cn
}

\section{Commission III, WG III/8}

KEY WORDS: Incident Surface Solar Radiation; Projection; RCP8.5; China; Tibetan Plateau

\begin{abstract}
:
We projected incident surface solar radiation (SSR) over China in the middle (2040-2059) and end (2080-2099) of the 21st century in the Representative Concentration Pathway (RCP) 8.5 scenario using a multi-model ensemble derived from the weighted average of seven global climate models (GCMs). The multi-model ensemble captured the contemporary (1979-2005) spatial and temporal characteristics of SSR and reproduced the long-term temporal evolution of the mean annual SSR in China. However, it tended to overestimate values compared to observations due to the absence of aerosol effects in the simulations. The future changes in SSR showed increases over eastern and southern China, and decreases over the Tibetan Plateau (TP) and northwest China relative to the present day. At the end of the 21 st century, there were SSR increases of 9-21 $\mathrm{W} \mathrm{m}^{-2}$ over northwest, central, and south China, and decreases of 18-30 $\mathrm{W} \mathrm{m}^{-2}$ over the TP in June-July-August (JJA). In northeast China, SSR showed seasonal variation with increases in JJA and decreases in December-January-February. The time series of annual SSR had a decreased linear trend for the TP, and a slightly increased trend for China during 2006-2099. The results of our study suggest that solar energy resources will likely decrease in the TP under future climate change scenarios.
\end{abstract}

\section{INTRODUCTION}

\subsection{General Instructions}

Incident surface solar radiation (SSR) is the fundamental energy source for the earth, directly influencing climate, the hydrologic cycle, ecological systems, and human life. SSR has been measured worldwide since the 1950s. Long-term records indicate lower values (also known as global dimming) during the 1950s-1980s and higher values (global brightening) during the 1980s-2000s (Wild et al., 2005). Decadal changes in SSR are correlated with temperature, which are also responsible for the absence of global warming in the 1950s-1980s (Stanhill and Cohen, 2001; Wild et al., 2007; 2009). Wang and Dickinson (2013) calculated that the decrease in SSR was responsible for a $>0.2^{\circ} \mathrm{C}$ decrease in mean temperature during May-October in the $1940 \mathrm{~s}-1970 \mathrm{~s}$, and a decrease around $0.2^{\circ} \mathrm{C}$ during November-April in the 1960s-1970s. However, the suppression of global warming through a decrease in SSR disappeared until the mid-1980s, when dimming gradually transformed into brightening (Wild et al., 2009). Since then, a marked and rapid increase in temperature (Wild et al., 2007) has transpired due to the greenhouse effect that has occurred concurrently with brightening.

Several studies have linked variation in SSR with the global water cycle (Liepert et al., 2004; Wild et al., 2008; Wang et al., 2010). Roderick and Farquhar (2002) reported that the decrease in evaporation was consistent with the observed decrease in SSR during the past 50 years, possibly because changes in SSR cause perturbations in the surface radiation and alter the energy available for evaporation (Wild et al. 2004). In addition, SSR is a major energy source for the melting of snow and ice, and has direct effects on cryospheric changes. Ohmura et al. (2007) found that the mass balance in Europe peaked around 19401980, and has drastically decreased since 1990. This is also consistent with decadal SSR variation (Wild et al., 2009). Solar dimming possibly counteracted the greenhouse effect through the 1980s, so that no significant changes in glacier size occurred in this period. However, it ended in the mid-1980s, and since then, greenhouse effects in combination with global brightening have caused accelerated melting, resulting in the rapid shrinkage of glaciers.

Solar dimming/brightening also significantly influences plant photosynthesis in terrestrial ecosystems. However, in addition to the total amount of SSR, diffuse radiation is also key in this context (Wild et al., 2009), as it reduces the increased atmospheric CO2 concentration (Farquhar and Roderick, 2003) and affects the global sink of terrestrial carbon (Mercado et al., 2009). Gu et al. (2003) estimated that diffuse radiation from the volcanic eruption of Mount Pinatubo in June 1991 enhanced photosynthetic production of a deciduous forest by $23 \%$ in 1992 and 8\% in 1993 in North America.

\footnotetext{
* Corresponding author: jizhm3@ mail.sysu.edu.cn
} 
As above mentioned, variation in SSR is considered crucial for understanding the decadal changes in various climatic factors on the Earth, which for the most part, can be detected from direct measurements (Augustine et al., 2000; Ackerman and Stokes, 2003; Philipona et al., 2004; Dutton et al., 2006), indirect proxy measurements (planetary albedo, diurnal temperature range, sunshine duration, and pan evaporation; Roderick and Farquhar, 2002; 2004; Harries et al., 2005; Abakumova et al., 2008; Sanchez-Lorenzo et al., 2008; Makowski et al., 2009; Palle et al., 2009; Wang and Dickinson, 2013; Liu et al., 2015; Manara et al., 2015), and satellitederived products (Pinker et al., 2005; Hinkelman et al., 2009; Zhang et al., 2015). Furthermore, global climate models (GCMs) are powerful tools for investigating the mechanisms and effects of decadal variation in SSR in the climate system (Romanou et al. 2007; Wild, 2008; Ruckstuhl and Norris, 2009). However, few studies have used GCMs, which are considered to be the only method that can predict changes in SSR under future climate scenarios (Wild et al., 2009; 2015). Wild et al. (2015) used a multi-model ensemble to predict changes in SSR during 2006-2049 under a climate change scenario of high greenhouse gas (GHG) emissions, although their study did not evaluate and validate the model's performance for the present-day climate.

Evaluating future changes in SSR increases our understanding of the possible impacts of climate change and provides an assessment of the potential effects on socio-economic development. For example, projections of SSR are useful to evaluate solar power (Burnett et al., 2014; Wild et al., 2015), which is considered an important form of energy supply due to its renewable and carbon-free properties, and offers an excellent option to meet the rapidly growing energy requirements in the context of emissions reductions in China during the next few decades. Therefore, in this study, we used an ensemble of multi-GCM outputs to validate their ability to simulate SSR in present-day China, and then predicted changes of SSR in a climate change scenario of high GHG emissions.

\section{DATA AND MODEL DESCRIPTION}

The simulated data were obtained from GCMs participating in Phase 5 of the Coupled Model Intercomparison Project (CMIP5; Taylor et al., 2012). CMIP5 provides a framework for coordinated climate change experiments for the assessment of the Fifth Intergovernmental Panel on Climate Change Assessment Report (IPCC AR5, 2013). In this study, the climate scenario used was Representative Concentration Pathway 8.5 (RCP8.5; Moss et al., 2010), which represents a high level of GHG emissions leading to radiative forcing of 8.5 $\mathrm{W} \mathrm{m}^{-2}$ at the end of the 21 st century (Riahi et al., 2011).

Seven GCMs listed in Table 1 were interpolated to $0.1^{\circ} \times 0.1^{\circ}$ grids using the bilinear method, and then combined as an ensemble by the weighted average. The selected seven GCMs were due to their better performance in terms of simulated climatology over East Asia (Xu and $\mathrm{Xu}, 2012)$. The following elements were analyzed: surface downward solar radiation under all-sky weather conditions, total cloud fraction and cloud height. The SSR data used to validate GCM performance were obtained from the Chinese regional surface meteorological features dataset developed by the Data Assimilation and Modeling Center for Tibetan Multi-spheres (Yang et al., 2010; Chen et al., 2011), which is based on the National Aeronautics and Space Administration/Global Energy and Water Cycle Experiment-Surface Radiation Budget (NASA/GEWEX-SRB) radiation data integrated with meteorological observations from the Chinese Meteorological Administration. More details are described in Yang et al. (2010) and references therein. The dataset covers the period of 1979-2010, with a temporal resolution of $3 \mathrm{~h}$ and a horizontal resolution of $0.1^{\circ} \times 0.1^{\circ}$. We defined the reference period representing contemporary climate from 1979 to 2005 . The projections for 2040-2059 and 2080 2099 were defined as the middle and end of the 21 st century, respectively.

\begin{tabular}{cccc}
\hline No. & Model & Resolution (Lon. $\times$ Lat.) & References \\
\hline 1 & CanESM2 & $2.81^{\circ} \times 2.81^{\circ}$ & Chylek et al. 2011 \\
2 & GFDL-ESM2M & $2.50^{\circ} \times 2.00^{\circ}$ & Dunne et al. 2012 \\
3 & IPSL-CM5A-LR & $3.75^{\circ} \times 1.88^{\circ}$ & Dufresne et al. 2013 \\
4 & MIROC-ESM & $2.81^{\circ} \times 2.81^{\circ}$ & Watanabe et al. 2011 \\
5 & MRI-ESM1 & $1.13^{\circ} \times 1.13^{\circ}$ & Yukimoto et al. 2011 \\
6 & NorESM1-ME & $2.50^{\circ} \times 1.88^{\circ}$ & Tjiputra et al. 2013 \\
7 & BCC-CSM1.1(m) & $1.13^{\circ} \times 1.13^{\circ}$ & Wu et al. 2010 \\
\hline
\end{tabular}

Table 1. Description of GCMs used in this study

\section{VALIDATION OF PERFORMANCE OF THE MULTI-MODEL ENSEMBLE}

To evaluate the performance of the multi-model ensemble, the simulated seasonal averaged SSR was compared to observations for each season (Figure 1). The spatial distribution of SSR showed an increase from southeast to northwest China and displayed topographical effects in the west. The highest SSR was located over the Tibetan Plateau (TP), whereas the lowest values occurred over the Sichuan Basin. Seasonal variation displayed maximum SSR values in June-July-August (JJA) and minimum values in December-January-February (DJF). In March-April-May (MAM), SSR ranged from 180 to $300 \mathrm{~W} \mathrm{~m}^{-2}$ over the TP, with the highest values over the west, and the lowest over the southeastern TP. Over the Yungui Plateau (located in southwest China) and northwest China, including Xinjiang and Inner Mongolia, SSR values ranged from 160 to $240 \mathrm{~W} \mathrm{~m}^{-2}$. In eastern China, SSR showed a zonal gradient with high values $\left(140-210 \mathrm{~W} \mathrm{~m}^{-2}\right)$ in the north and low values $(120$ $160 \mathrm{~W} \mathrm{~m}^{-2}$ ) in the south of the Yangtze River. In the Sichuan Basin where the lowest SSR values occurred, SSR reached 120 $\mathrm{W} \mathrm{m}{ }^{-2}$ in MAM. In JJA, the spatial distribution of SSR across China showed a similar pattern, but with higher values compared to MAM. The maximum SSR increased to 180-220 $\mathrm{W} \mathrm{m}{ }^{-2}$ in south China. In northwestern China and the TP, SSR increased by $20-30 \mathrm{~W} \mathrm{~m}^{-2}$ in JJA compared to MAM. It should be noted that SSR began to decrease in September-OctoberNovember (SON), and the values were in the range of 160 to $240 \mathrm{~W} \mathrm{~m}^{-2}$ over the TP, and 90 to $120 \mathrm{~W} \mathrm{~m}^{-2}$ over the Sichuan Basin. The lowest solar radiation decreased by $60-120 \mathrm{~W} \mathrm{~m}^{-2}$ compared to JJA, and occurred in DJF over most regions of China.

A comparison between simulations and observations indicated that the multi-model ensemble performed well in terms of the spatial distribution and seasonal cycle of SSR in China. For example, low SSR over the southeastern TP in JJA due to the extensive cloud coverage caused by the Indian summer monsoon was reproduced reasonably well in the simulations. However, the multi-model ensemble tended to overestimate observed SSR values. The root mean-square deviation (RMSD) of the simulated SSR ranged from 0 to $20 \mathrm{~W} \mathrm{~m}^{-2}$ in the TP and 
northwest Chino, and from 20 to $70 \mathrm{~W} \mathrm{~m}^{-2}$ in southern and eastern China across all of the seasons.

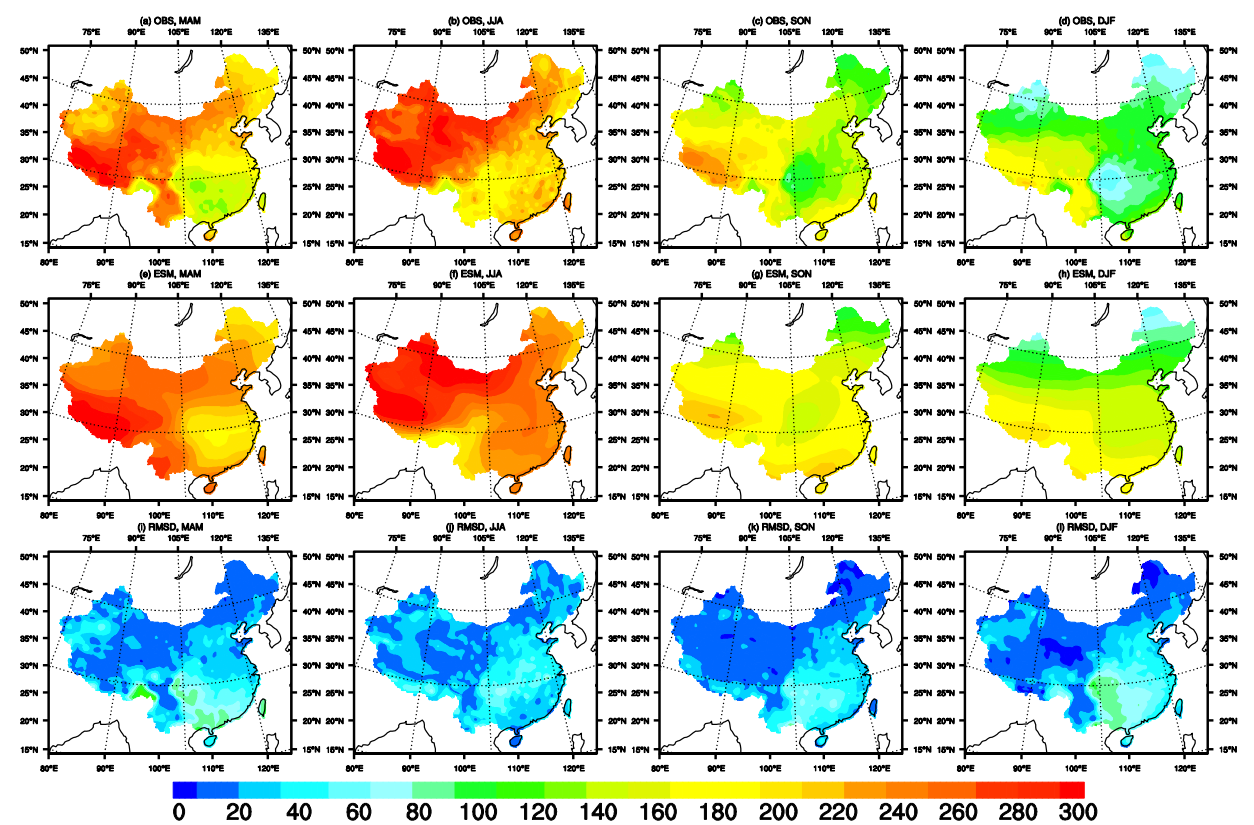

Figure 1. Seasonal average SSR (units: $\mathrm{W} \mathrm{m}^{-2}$ ). Observations (first row), simulations (second row), RMSD (third row). MAM, JJA, $\mathrm{SON}$, and DJF are presented in each column from left to right.

The highest overestimates of simulated SSR were in the Sichuan Basin in DJF, where the RSMD reached $80 \mathrm{~W} \mathrm{~m}^{-2}$. The biases are probably due to the fact that the historical ensemble experiments did not consider the effects of aerosols, which significantly contribute to the reduction in SSR over China (Menon et al., 2002; Qian et al., 2006; Guo et al., 2011; Liu et al., 2015). They can change SSR by scattering and/or absorbing solar radiation in the atmosphere depending on their optical properties (Lacis and Hansen, 1974). In addition, aerosol particles acting as cloud condensation nuclei $(\mathrm{CCN})$ can modify SSR by altering a cloud's optical properties and lifetime (Haywood and Boucher, 2000).

The interannual variability of SSR can be represented by standard deviation (SD). The SD of observed SSR showed a decreasing trend from southeast to northwest China (Figure 2). The maximum SD occurred in south China in JJA, with values between 18 and $22 \mathrm{~W} \mathrm{~m}^{-2}$. The SD of SSR was $<6 \mathrm{~W} \mathrm{~m}^{-2}$ in SON and DJF over the TP (excluding the southeastern TP), Xinjiang, and Inner Mongolia, whereas values were between 6 and $16 \mathrm{~W} \mathrm{~m}^{-2}$ in southern China. Compared to observations, the multi-model ensemble satisfactorily reproduced the general observed spatial patterns of high SD in southwest, and low values in northwest China. However, the simulated SD was significantly underestimated, with biases in the range of 8 to 10 $\mathrm{W} \mathrm{m}^{-2}$ in south China. It should be noted that the model's performance for simulating interannual variability was not as accurate as for simulating climatic average. As discussed above, the simulations for the reference period did not include aerosol effects, which are considered to be one of the most significant factors affecting variation in SSR. Aerosol emissions have increased during recent decades in accordance with socioeconomic development, which would have significant effects on the interannual variation in SSR over China.

The observed annual mean SSR was lower during 1979-1989, and then stabilized and was slightly higher from 1990 to 2005 (Figure 3a). The linear trend in observed SSR has shown lower values during recent decades, which is consistent with in situ observations reported in previous studies (Che et al., 2005; Shi et al., 2008; Tang et al., 2011; 2013). The multi-model ensemble was able to reproduce a slightly lower linear trend in annual mean SSR. However, the simulations failed to capture the inflection (in 1989/1990) in the time evolution of annual averaged SSR. Furthermore, the multi-model ensemble overestimated SSR values and produced less interannual variability compared to observations due to the simulations excluding the effects of aerosols. Monthly averaged simulated SSR yielded higher values in JJA and lower values in DJF (Figure 3b), which corresponded to the seasonal variation in spatial distribution. Hence, the simulations were able to reproduce the monthly variation, but with overestimates compared to observations. Overall, the multi-model ensemble was capable of capturing the spatial and temporal features of SSR in China. Comparison with observations showed some biases, such as overestimation of the seasonal mean values, and underestimation of the interannual variability in SSR over eastern and southern China. These discrepancies are probably due to the fact that the simulations did not include the effects of aerosols, which can reduce solar radiation in the atmosphere. Nevertheless, we conclude that the multi-model ensemble performs well for application to climate change studies. 


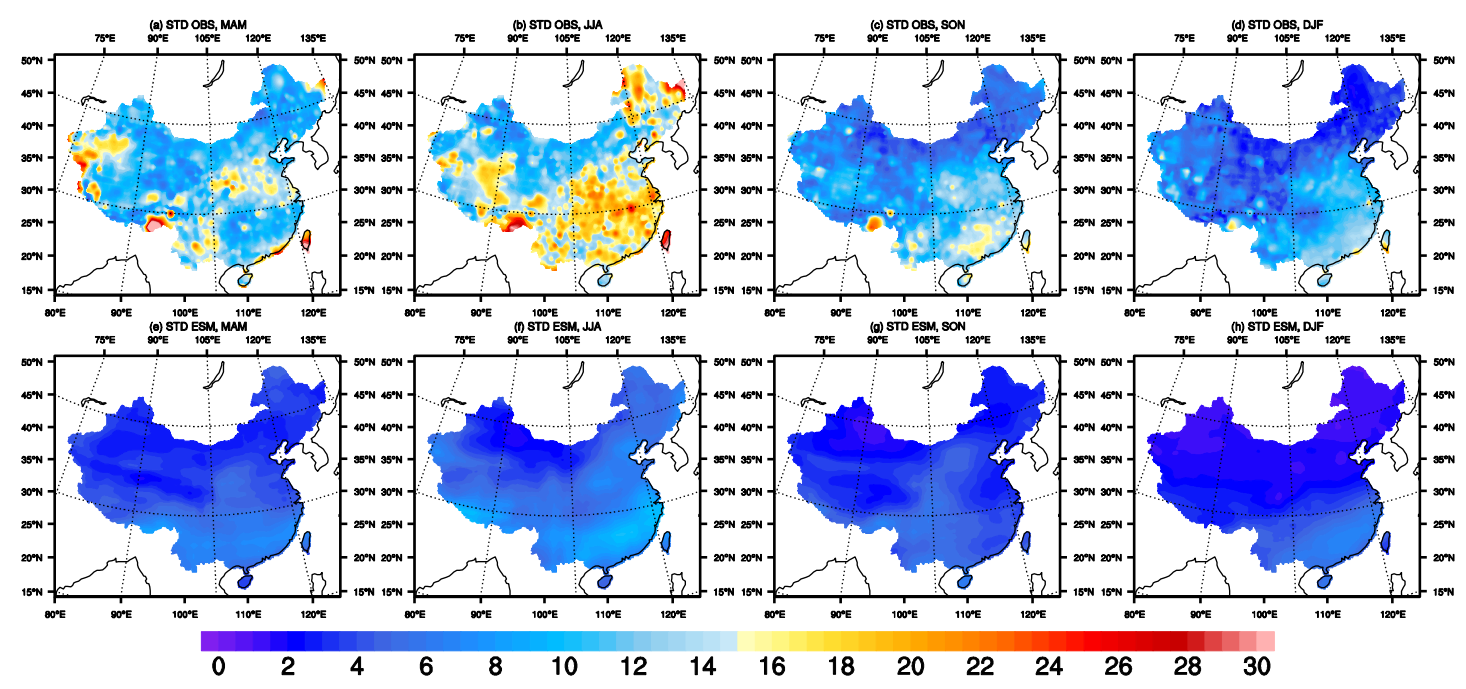

Figure 2. Standard deviation of SSR for observations (first row) and simulations (second row). MAM, JJA, SON, and DJF are presented in each row from top to bottom.
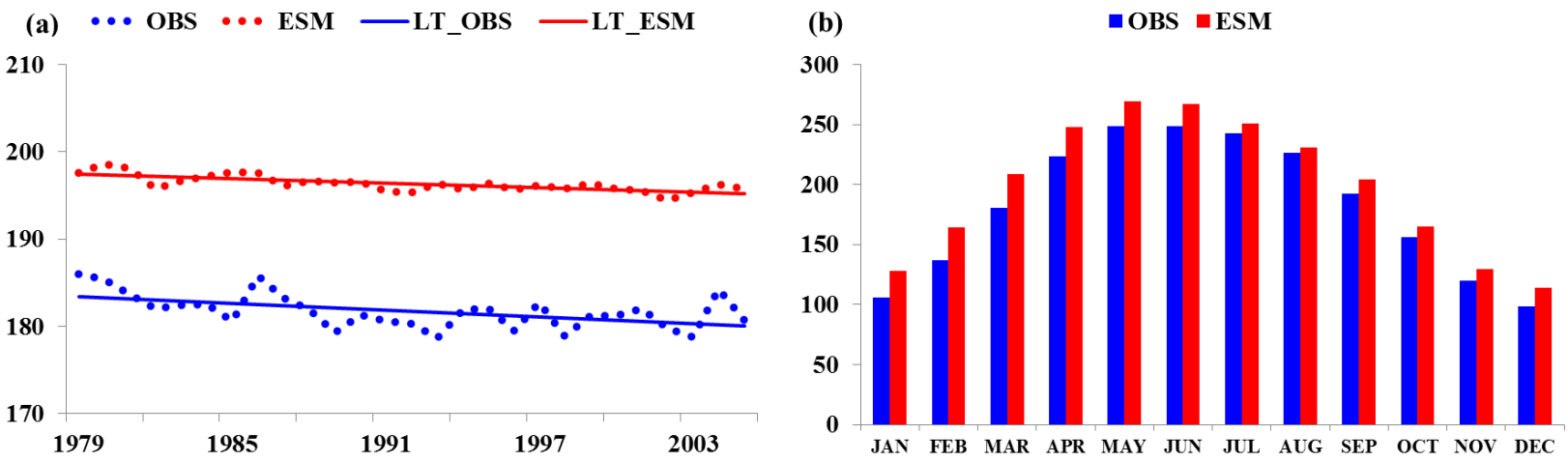

Figure 3. Time series of area-averaged SSR over China (units: $\mathrm{W} \mathrm{m}^{-2}$ ). (a) annual; (b) monthly

\section{PROJECTION OF SSR UNDER THE RCP8.5 SCENARIO}

The changes in spatial distribution of SSR in the mid- and endterm of the 21st century relative to 1979-2005 are shown in Figure 4. SSR was increased over southern and eastern China in each season. In northwest China and the TP, SSR was decreased throughout the year. In the mid-term, the greatest variation occurred in JJA and showed significant decreases of 3-18 W m-2 over the TP and northwestern China, and increases of 3-15 W m-2 over northeast, east, central, and south China. In MAN and SON, changes in SSR displayed a similar spatial distribution, but with a smaller magnitude compared to those in JJA. In DJF, SSR decreased by 3-9 $\mathrm{W} \mathrm{m}-2$ over the TP and north China, and increased by $3-12 \mathrm{~W} \mathrm{~m}-2$ over southeast China. In the end-term, the changes in SSR showed a similar spatial distribution to the mid-term; however, they were greater compared to the mid-term. For example, decreases in SSR varied from 18 to $30 \mathrm{~W} \mathrm{m-2}$ over the TP in JJA in the end-term relative to the reference period. Changes in SSR are likely caused by variation in clouds in the RCP8.5 scenario. In northeast, central, east, and south China, changes in total cloud fraction had a significant impact on SSR variation. For example, in DJF, the decreased total cloud fraction led to a decrease in SSR over northeast China, whereas the increased total cloud fraction led to decreases in SSR over south and east China.
However, it should be noted that no correlation between SSR and total cloud fraction was observed over the TP and parts of northwestern China (e.g., reduced total cloud fraction did not result in higher SSR over the TP in MAM). Yang et al. (2012) reported that the total cloud fraction was not a predominant factor leading to SSR variation over the TP, and that solar dimming over the plateau was probably due to an increase in water vapor and deep convective cloud.Based on satellite data and surface meteorological observations, Li et al. (2004) reported that the total cloud fraction over the TP and northwest China was significantly lower than that over southern and eastern China. However, convective clouds accounted for nearly $50 \%$ of the low cloud coverage in the TP and northwest China, which should act as a primary factor affecting SSR variation. Over the TP, total cloud fraction decreased slightly, whereas average cloud thickness was significantly deeper due to more significant convective events induced by warming in the RCP8.5 scenario. The combined effects of these processes caused a decrease in SSR over the TP.However, in the plain regions, increased cloud thickness was unable to offset the effect of SSR increases caused by significant decreases in total cloud fraction in the future relative to the present-day scenario. We suggest that changes in total cloud fraction can be used to explain variation in SSR over south and east China, whereas 


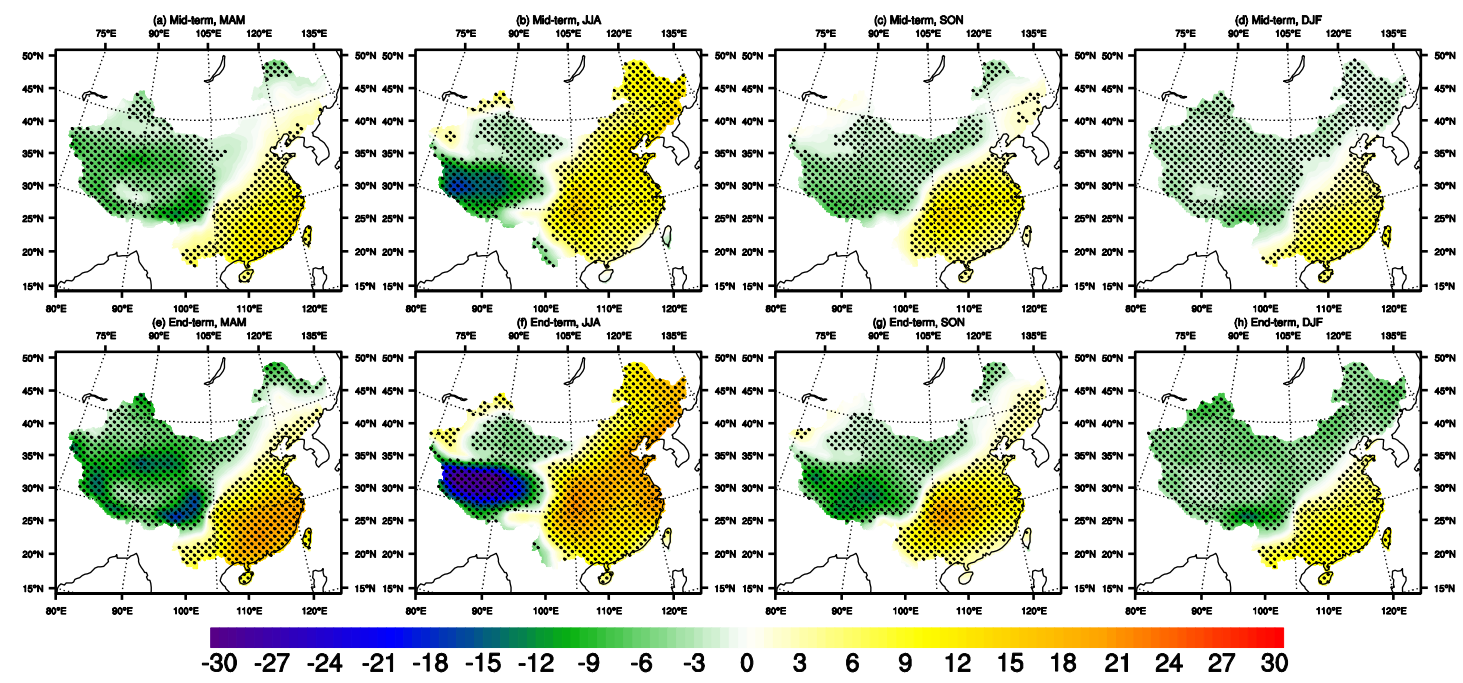

Figure 4. Changes in SSR (units: $\mathrm{W} \mathrm{m}^{-2}$ ) in the mid-term (first row) and end-term (second row) of the 21st century relative to 19792005. MAM, JJA, SON, and DJF are presented in each column from left to right. Regions of statistical significance > $95 \%$ level are stippled.

SSR should be associated with convective clouds over the TP and northwest China.

Changes (relative to the reference period) in annual SSR averaged over area in China and the TP showed different patterns during 2006-2099 (Figure 5a). For the entire area of China, average annual SSR was decreased in 2006-2030, and then was slightly increased through 2099; however, the SSR values were low, in the range of -2 to $2 \mathrm{~W} \mathrm{~m}^{-2}$. The values of SSR averaged over area showed small changes relative to the significant spatial difference in the variation in SSR between northwestern (increased SSR) and southeastern (decreased SSR) China. For the TP, changes in SSR averaged were larger than those for the entire area of China, and showed gradual decreases from 2006 to 2099, which also corresponded to variation in the

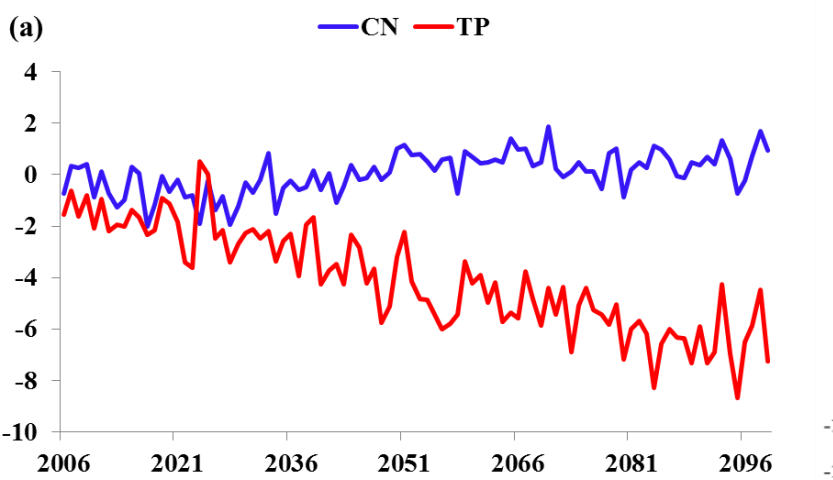

spatial patterns of SSR over the TP. In the end-term of the $21 \mathrm{st}$ century, the area-averaged SSR values decreased by $4-8 \mathrm{~W} \mathrm{~m}^{-2}$ compared to those in the reference period. The changes in monthly averaged SSR also differed between entire China and the TP (Figure 5b). For China, the monthly mean SSR only showed increases from May to September, with a maximum increase in $2 \mathrm{~W} \mathrm{~m}^{-2}$ occurring in July for the mid-term, and of $4.5 \mathrm{~W} \mathrm{~m}^{-2}$ in June for the end-term. In the other months, the decreases in SSR were in the range of 0 to $2 \mathrm{~W} \mathrm{~m}^{-2}$. For the TP, monthly averaged SSR was decreased throughout the year. The lowest value of $8 \mathrm{~W} \mathrm{~m}^{-2}$ occurred in August for the mid-term, and of $10.5 \mathrm{~W} \mathrm{~m}^{-2}$ in June for the end-term. Changes in monthly averaged SSR in the end-term showed a similar pattern, but were larger than those in the mid-term.

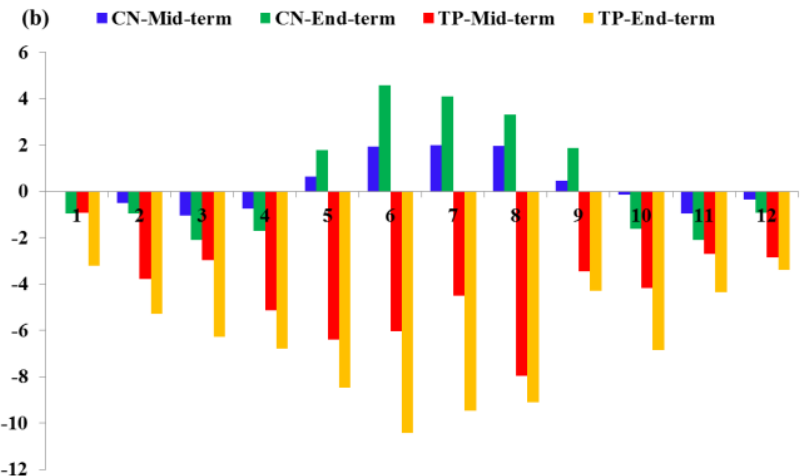

Figure 5. Time evolution of changes in area-averaged SSR over China (units: $\mathrm{W} \mathrm{m}^{-2}$ ) relative to the reference period. (a) annual; (b) monthly

\section{SUMMARY AND CONCLUSIONS}

Incident SSR is a key factor influencing climate system. However, few studies have focused on projections of SSR under future climate change scenarios, or the potential impacts of global warming on SSR variation. In this study, a multi-model ensemble derived from the weighted average of seven GCMs from CMIP5 was used to investigate changes in SSR over
China in the RCP8.5 scenario. The multi-model ensemble performed well in reproducing the spatial distribution of SSR in each season. The simulations reproduced the observed decreased values in annual mean SSR during 1979-2005 and provided reasonable values of the monthly variation. Due to the fact that the modeling experiments did not consider the dimming effects of aerosols, both the spatial distribution and annual/monthly temporal evolution from the simulations 
produced overestimates compared to observations, which led to underestimates of the interannual variability of SSR.

SSR increased over south and east China, but decreased over the TP and northwest China in the mid-term of the 21 st century relative to the present day, which was similar to the spatial patterns in the end-term, with higher variation. The greatest increases in SSR occurred over the TP in JJA in the end-term, with values between 18 and $30 \mathrm{~W} \mathrm{~m}^{-2}$. The spatial variation in SSR in northeast China displayed seasonal variation, with increases in JJA and decreases in DJF. Annual SSR was characterized by significantly lower values averaged by area for the TP, and a slightly increased pattern for entire China during 2006-2099 relative to the reference period. Monthly SSR variation showed increases of $2-4 \mathrm{~W} \mathrm{~m}^{-2}$ in $\mathrm{JJA}$ for areaaveraged values for all of China, and decreases of 4-10 $\mathrm{W} \mathrm{m}^{-2}$ for the TP. The changes in SSR had different patterns between the TP and east China, which is probably due to differences in the effects of clouds caused by warming in the RCP8.5 scenario. The decrease in the total cloud fraction led to predominantly higher SSR over eastern and southern China. In the TP, enhanced convective events increased average cloud thickness, which is also considered to be an important factor for decreasing SSR.

Since the 1980s, numerous solar energy projects have been promoted on the TP. Currently, as the region in China with the most solar energy resources, about 400 solar photovoltaics power plants are located in Tibet (Cai and Zhang, 2006). In addition, solar thermal energy is widely applied through solar heaters, cookers, and in buildings. Our results imply that solar energy resources will decrease in the TP in future climate change scenarios, which will likely impact the promotion of carbon-free and clean energy.

It should also be noted that the effects of aerosols (absorbing and scattering optical properties) and variation in land cover, which are considered to be two key factors affecting SSR, were not taken into account in this study. Further studies are required that focus on evaluating the contributions of these factors to variation in SSR, which will further our understanding of the mechanisms derived from anthropogenic perturbations and their effects on climate changes in the future.

\section{ACKNOWLEDGEMENTS}

This study is supported by the National Key Research and Development Program of China (Grant No. 2016YFA0602701), the National Natural Science Foundation of China (Grant No. 91644225). The observation of SSR was provided from Data Assimilation and Modeling Center for Tibetan Multi-spheres, Institute of Tibetan Plateau Research, Chinese Academy of Sciences. We acknowledge the World Climate Research Programme's Working Group on Coupled Modelling, which is responsible for CMIP, and we thank the climate modeling groups (listed in Table 1 of this paper) for producing and making available their model output. For CMIP the U.S. Department of Energy's Program for Climate Model Diagnosis and Intercomparison provides coordinating support and led development of software infrastructure in partnership with the Global Organization for Earth System Science Portals.

\section{REFERENCES}

Abakumova, G.M., Gorbarenko, E.V., Nezval, E.I., Shilovtseva, O.A., 2008. Fifty years of actinometrical measurements in Moscow. Int. J. Remote Sens., 29, 2629-2665, doi:10.1080/01431160701767500.

Ackerman, T.P., Stokes, G.M., 2003. The atmospheric radiation measurement program, Phys. Today, 56, 38- 44, doi:10.1063/1.1554135.

Augustine, J.A., DeLuisi, J.J., Long, C.N., 2000. SURFRAD: A national surface radiation budget network for atmospheric research. Bull.Am. Meteorol. Soc., 81, 2341-2358,

Burnett, D., Barbour, E., Harrison, G.P., 2014. The UK solar energy resource and the impact of climate change. Renewable Energy 71, 333-343.

Cai, G.T., Zhang, L., 2006. The Research on Tibet's Energy Use and Development. Energy of China 28(1): 38-42 Doi: 10.3969/j.issn.1003-2355.2006.01.009. (in Chinese)

Che, H. Z., Shi, G.Y., Zhang, X.Y., et al., 2005. Analysis of 40 years of solar radiation data from China, 1961-2000. Geophysical Research Letters, 32 (6). L06803, doi: 10.1029/2004GL022322

Chen, Y.Y., Yang, K., He, J., Qin, J., Shi, J.C., Du, J.Y., He, Q., 2011. Improving land surface temperature modeling for dry land of China. J. Geophys. Res., 116, D20104, doi:10.1029/2011JD015921.

Chylek, P., Li, J., Dubey, M.K., Wang, M., Lesins, G., 2011. Observed and model simulated 20th century Arctic temperature variability: Canadian Earth System Model CanESM2, Atmos. Chem. Phys. Discuss., 11(8), 22,893-22,907, doi:10.5194/acpd11-22893-2011.

Dufresne, J.L., Foujols, M.A., Denvil, S., et al., 2013. Climate change projections using the IPSL-CM5 Earth System Model: From CMIP3 to CMIP5, Clim. Dyn., 40 (9-10), 2123-2165, doi:10.1007/s00382-012-1636-1.

Dunne, J.P., John, J.G., Adcroft, A.J., et al., 2012. GFDL's ESM2 global coupled climate-carbon Earth System Models. Part I: Physical formulation and baseline simulation characteristics, J. Clim., 25(19), 6646-6665, doi:10.1175/jcli-d11-00560.1.

Dutton, E.G., Nelson, D.W., Stone, R.S., Longenecker, D., Carbaugh, G., Harris, J.M., Wendell, J., 2006. Decadal, variations in surface solar irradiance as observed in a globally remote network, J. Geophys. Res., 111, D19101, doi:10.1029/2005JD006901.

Farquhar, G.D., Roderick, M.L., 2003. Pinatubo, diffuse light, and the carbon cycle. Science, 299: 1997-1998

Gu, L.H., Baldocchi, D.D., Wofsy, S.C., William, Munger, J., Michalsky, J.J., Urbanski, S.P., Boden, T.A., 2003. Response of a deciduous forest to the Mount Pinatubo eruption: Enhanced 
photosynthesis, Science, 299, $2035 \quad-\quad 2038$, doi:10.1126/science.1078366.

Guo, J.P., Zhang, X.Y., Wu, Y.R., et al., 2011. Spatio-temporal variation trends of satellite-based aerosol optical depth in China during 1980-2008. Atmospheric Environment, 45 (37), 68026811 .

Harries, J.E., Russell, J.E., Hanafin, J.A., et al., 2005. The Geostationary Earth Radiation Budget Project, Bull. Am. Meteorol. Soc., 86, 945-960, doi:10.1175/BAMS-86-7-945

Hinkelman, L.M., Stackhouse, Jr. P.W., Wielicki, B.A., Zhang, T., Wilson, S.R., 2009. Surface insolation trends from satellite and ground measurements: Comparisons and challenges, $J$. Geophys. Res., doi:10.1029/2008JD011004,

IPCC, 2013. Climate Change 2013: The Physical Science Basis. Contribution of Working Group I to the Fifth Assessment Report of the Intergovernmental Panel on Climate Change Cambridge, United Kingdom and New York, NY, USA.

Lacis, A.A., Hansen, J., 1974. A parameterization for the absorption of solar radiation in the earth's atmosphere. Journal of the Atmospheric Sciences, 31(1), 118-133.

Li, Y., Yu, R., Xu, Y., Zhang, X., 2004. Spatial distribution and seasonal variation of cloud over China based on ISCCP data and surface observations. Journal of the Meteorological Society of Japan, 82(2), 761-773.

Liepert, B.G., Feichter, J., Lohmann, U., Roeckner, E., 2004. Can aerosols spin down the water cycle in a warmer and moister world?, Geophys. Res. Lett., 31, L06207, doi:10.1029/2003GL019060.

Liu, J., Linderholm, H., Chen, D., et al., 2015. Changes in the relationship between solar radiation and sunshine duration in large cities of China. Energy, 82, 589-600.

Liu, J.D., Linderholm, H., Chen, D.L., Zhou, X.J., Flerchinger, G.N., Yu, Q., Du, J., Wu, D.R., Shen, Y.B., Yang, Z.B., 2015. Changes in the relationship between solar radiation and sunshine duration in large cities of China. Energy 82, 589-600.

Makowski, K., Jager, E., Chiacchio, M., Wild, M., Tracy, E., Ohmura, A., 2009. On the relationship between diurnal temperature range and surface solar radiation in Europe, $J$. Geophys. Res., 114, D00D07, doi:10.1029/2008JD011104.

Manara, V., Beltrano, M.C., Brunetti, M., Maugeri, M., Sanchez-Lorenzo, A., Simolo, C., Sorrenti, S., 2015. Sunshine duration variability and trends in Italy from homogenized instrumental time series (1936-2013). Journal of Geophysical Research: Atmospheres 120:10.1002/jgrd.v120.9, 3622-3641.

Menon, S., Hansen, J., Nazarenko, L., Luo, Y.F., 2002. Climate effects of black carbon aerosols in China and India. Science, 297 (5590), 2250-2253.

Mercado, L.M., Bellouin, N., Sitch, S., Boucher, O., Huntingford, C., Wild, M., Cox, P.M., 2009. Impact of changes in diffuse radiation on the global land carbon sink, Nature, 458, 1014- 1017, doi:10.1038/nature07949.
Moss, R.H., Edmonds, J.A., Hibbard, K.A., Manning, M.R., Rose, S.K., van, Vuuren, D.P., Carter, T.R., Emori, S., Kainuma, M., Kram, T., Meehl, A., Mitchell, J.F.B., Nakicenovic, N., Riahi, K., Smith, S.J., Ronald, Stouffer, R.J., Thomson, A.M., Weyant, J.P., Wilbanks, T.J., 2010. The next generation of scenarios for climate change research and assessment. Nature 463(7282):747-756

Ohmura, A., Bauder, A., Mueller, H., Kappenberger, G., 2007. Long term change of mass balance and the role of radiation, Ann. Glaciol., 46, 367-374, doi:10.3189/172756407782871297.

Palle, E., Goode, P.R., Montanes-Rodriguez, P., 2009. Interannual variations in Earth's reflectance $1999-2007, J$. Geophys. Res., 114, D00D03, doi:10.1029/2008JD010734.

Philipona, R., Durr, B., Marty, C., Ohmura, A., Wild, M., 2004. Radiative forcing -measured at Earth's surface - corroborate the increasing greenhouse effect, Geophys. Res. Lett., 31, L03202, doi:10.1029/2003GL018765.

Pinker, R.T., Zhang, B., Dutton, E.G., 2005. Do satellites detect trends in surface solar radiation?, Science, 308, 850 - 854, doi:10.1126/science.1103159.

Qian, Y., Kaiser, D.P., Leung, L.R., Xu, M., 2006. More frequent cloud-free sky and less surface solar radiation in China from 1955 to 2000. Geophysical Research Letters, 33 (1), L01812, doi:10.1029/2005GL024586

Riahi, K., Rao, S., Krey, V., Cho, C., Chirkov, V., Fischer, G., Kindermann, G., Nakicenovic, N., Rafaj, P., 2011. RCP 8.5-A scenario of comparatively high greenhouse gas emissions. Clim Change 109:33-57. doi:10.1007/s10584-011-0149-y

Roderick, M.L., Farquhar, G.D., 2002. The cause of decreased pan evaporation over the past 50 years, Science, 298, 1410 1411

Roderick, M.L., Farquhar, G.D., 2004. Changes in Australian pan evaporation from 1970 to 2002, Int. J. Climatol., 24, 1077 1090, doi:10.1002/joc.1061.

Romanou, A., Liepert, B., Schmidt, G.A., Rossow, W.B., Ruedy, R.A., Zhang Y., 2007. 20th century changes in surface solar irradiance in simulations and observations, Geophys. Res. Lett., 34, L05713, doi:10.1029/2006GL028356.

Ruckstuhl, C., Norris, J., 2009. How do aerosol histories affect solar "dimming", and "brightening", over Europe?: IPCC-AR4 models versus observations, J. Geophys. Res., 114, D00D04, doi:10.1029/2008JD011066.

Sanchez-Lorenzo, A., Calbó, J., Martin-Vide, M., 2008. Time evolution of sunshine duration over western Europe (19382004), J. Clim., 21, 6089- 6098, doi:10.1175/2008JCLI2442.1

Shi, G.Y., Hayasaka, T., Ohmura, A., et al., 2008. Data quality assessment and the long-term trend of ground solar radiation in China. Journal of Applied Meteorology and Climatology, 47(4), 1006-1016.

Stanhill, G., Cohen, S., 2001. Global dimming: A review of the evidence for a widespread and significant reduction in global 
radiation, Agric. For. Meteorol., 107, 255-278, doi:10.1016/S0168-1923(00)00241-0.

Tang, W., Yang, K., Qin, J., Cheng, C., He, J., 2011. Solar radiation trend across China in recent decades: a revisit with quality-controlled data, Atmos. Chem. Phys., 11, 393-406,

Tang, W., Yang, K., Qin, J., Min, M., 2013. Development of a 50-year daily surface solar radiation dataset over China, Sci. China Ser. D, 56(9), 1555-1565, doi:10.1007/s11430-012-45429.

Taylor, K.E., Stouffer, R.J., Meehl, G.A., 2012. An overview of CMIP5 and the experiment design. Bull Am Meteorol Soc 93:485-498. doi:10.1175/BAMS-D-11-00094.1

Tjiputra, J.F., Roelandt, C., Bentsen, M., Lawrence, D.M., Lorentzen, T., Schwinger, J., Seland, Ø., Heinze, C., 2013. Evaluation of the carbon cycle components in the Norwegian Earth System Model (NorESM), Geosci. Model Dev., 6(2), 301-325, doi:10.5194/gmd-6-301-2013.

Wang, K., Dickinson, R.E., 2013. Contribution of solar radiation to decadal temperature variability over land. Proceedings of the National Academy of Sciences, 110(37), 14877-14882.

Wang, K., Dickinson, R.E., Wild, M., Liang, S., 2010. Evidence for decadal variation in global terrestrial evapotranspiration between 1982 and 2002: 2. Results, $J$. Geophys. Res., 115, D20113, doi:10.1029/2010JD013847

Watanabe, S., Hajima, T., Sudo, K., et al., 2011. MIROC-ESM 2010: Model description and basic results of CMIP5-20c3m experiments, Geosci. Model Dev., 4 (4), 845-872, doi:10.5194/gmd-4-845-2011.

Wild, M., 2008. Decadal changes in surface radiative fluxes and their importance in the context of global climate change, in Climate Variability and Extremes During the Past 100 Years, Adv. Global Change Res. Ser., 33, edited by S. Bronnimann et al., pp. 155-167, Springer, New York.

Wild, M., Folini, D., Henschel, F., Fischer, N., Müller, B., 2015. Projections of long-term changes in solar radiation based on CMIP5 climate models and their influence on energy yields of photovoltaic systems. Solar Energy 116, 12-24.

Wild, M., Gilgen, H., Roesch, A., Ohmura, A., Long, C.N., Dutton, E.G., Forgan, B., Kallis, A., Russak, V., Tsvetkov, A., 2005. From dimming to brightening: Decadal changes in surface solar radiation, Science, 308, 847-850, doi:10.1126/science.1103215.

Wild, M., Grieser, J., Schar, C., 2008. Combined surface solar brightening and increasing greenhouse effect support recent intensification of the global land-based hydrological cycle, Geophys. Res. Lett., 35, L17706, doi:10.1029/2008GL034842.

Wild, M., Ohmura, A., Gilgen, H., Rosenfeld, D., 2004. On the consistency of trends in radiation and temperature records and implications for the global hydrological cycle, Geophys. Res. Lett., 31, L11201, doi:10.1029/2003GL019188.
Wild, M., Ohmura, A., Makowski, K., 2007. Impact of global dimming and brightening on global warming, Geophys. Res. Lett., 34, L04702, doi:10.1029/2006GL028031.

Wild, M., Trussel, B., Ohmura, A., Long, C.N., Dutton, E.G., Konig-Langlo, G., Tsvetkov, A., 2009. Global dimming and brightening: An update beyond 2000, J. Geophys. Res., 114, D00D13, doi:10.1029/2008JD011382.

Wu, T., Yu, R., Zhang, F., Wang, Z., Dong, M., Wang, L., Jin, X., Chen, D., Li, L., 2010. The Beijing Climate Center atmospheric general circulation model: Description and its performance for the present-day climate, Clim. Dyn., 34(1), 123-147, doi:10.1007/s00382-008-0487-2.

$\mathrm{Xu}$, C.H., Xu, Y., 2012. The projection of temperature and precipitation over China under RCP scenarios using a CMIP5 multi-model ensemble." Atmospheric and Oceanic Science Letters, 5.6: 527-533.

Yang, K., Ding, B., Qin, J., Tang, W., Lu, N., Lin, C., 2012. Can aerosol loading explain the solar dimming over the Tibetan Plateau?, Geophys. Res. Lett., 39, L20710, doi:10.1029/2012GL053733.

Yang, K., He, J., Tang, W.J., Qin, J., Cheng, C.C.K., 2010. On downward shortwave and longwave radiations over high altitude regions: Observation and modeling in the Tibetan Plateau. Agric. Forest. Meteorol, 150, 38-46.

Yukimoto, S., Adachi, Y., Hosaka, M., et al., 2011. A new global climate model of the meteorological research institute: MRI-CGCM3-Model description and basic performance, $J$. Meteor. Soc., 90A, 23-64, doi:10.2151/jmsj.2012-A02

Zhang, X.T., Liang, S.L., Wild, M., Jiang, B., 2015. Analysis of surface incident shortwave radiation from four satellite products. Remote Sensing of Environment 165, 186-202. 